\title{
Complement factor $B$ regulates cellular senescence and is associated with poor prognosis in pancreatic cancer
}

\author{
Reiri Shimazaki ${ }^{1} \cdot$ Shigetsugu Takano ${ }^{1}$ (D) $\cdot$ Mamoru Satoh $^{2} \cdot$ Mamoru Takada $^{1} \cdot$ Yoji Miyahara $^{1} \cdot$ Kosuke Sasaki $^{1} \cdot$ \\ Hideyuki Yoshitomi ${ }^{1}$. Shingo Kagawa ${ }^{1}$ - Katsunori Furukawa ${ }^{1} \cdot$ Tsukasa Takayashiki $^{1}$ - Satoshi Kuboki ${ }^{1}$. \\ Kazuyuki Sogawa ${ }^{3} \cdot$ Shinichiro Motohashi $^{4} \cdot$ Fumio Nomura $^{2} \cdot$ Masaru Miyazaki $^{1} \cdot$ Masayuki Ohtsuka $^{1}$
}

Received: 20 November 2020 / Accepted: 19 May 2021 / Published online: 1 June 2021

(C) The Author(s) 2021

\begin{abstract}
Background The interplay between cancer cells and stromal components, including soluble mediators released from cancer cells, contributes to the progression of pancreatic ductal adenocarcinoma (PDAC). Here, we set out to identify key secreted proteins involved in PDAC progression.

Methods We performed secretome analyses of culture media of mouse pancreatic intraepithelial neoplasia (PanIN) and PDAC cells using Stable Isotope Labeling by Amino acid in Cell culture (SILAC) with click chemistry and liquid chromatography-mass spectrometry (LC-MS/MS). The results obtained were verified in primary PDAC tissue samples and cell line models.

Results Complement factor B (CFB) was identified as one of the robustly upregulated proteins, and found to exhibit elevated expression in PDAC cells compared to PanIN cells. Endogenous CFB knockdown by a specific siRNA dramatically decreased the proliferation of PDAC cells, PANC-1 and MIA PaCa-II. CFB knockdown induced increases in the number of senescenceassociated- $\beta$-galactosidase (SA- $\beta$-gal) positive cells exhibiting p21 expression upregulation, which promotes cellular senescence with cyclinD1 accumulation. Furthermore, CFB knockdown facilitated downregulation of proliferating cell nuclear antigen and led to cell cycle arrest in the G1 phase in PDAC cells. Using immunohistochemistry, we found that high stromal CFB expression was associated with unfavorable clinical outcomes with hematogenous dissemination after surgery in human PDAC patients. Despite the presence of enriched $\mathrm{CD}^{+}$tumor infiltrating lymphocytes in the PDAC tumor microenvironments, patients with a high stromal CFB expression exhibited a significantly poorer prognosis compared to those with a low stromal CFB expression. Immunofluorescence staining revealed a correlation between stromal CFB expression in the tumor microenvironment and an enrichment of immunosuppressive regulatory T-cells (Tregs), myeloid-derived suppressor cells (MDSCs) and tumor-associated macrophages (TAMs). We also found that high stromal CFB expression showed a positive correlation with high $\mathrm{CD}^{+} / \mathrm{Foxp}^{+}$Tregs populations in PDAC tissues. Conclusions Our data indicate that CFB, a key secreted protein, promotes proliferation by preventing cellular senescence and is associated with immunological tumor promotion in PDAC. These findings suggest that CFB may be a potential target for the treatment of PDAC.
\end{abstract}

Keywords Pancreatic ductal adenocarcinoma $\cdot$ Secreted protein $\cdot$ Complement factor B $\cdot$ Proliferation $\cdot$ Senescence $\cdot$ p21 . Regulatory T-cells

Shigetsugu Takano

stakano@faculty.chiba-u.jp

1 Department of General Surgery, Graduate School of Medicine, Chiba University, 1-8-1, Inohana, Chuo-ku, Chiba-shi, Chiba 260- 8677, Japan

2 Division of Clinical Mass Spectrometry, Chiba University Hospital, Chiba 260-8677, Japan

3 Department of Biochemistry, School of Life and Environmental Science, Azabu University, 252-5201 Kanagawa, Japan

4 Department of Medical Immunology, Graduate School of Medicine, Chiba University, 260-8677 Chiba, Japan

\section{Introduction}

Pancreatic ductal adenocarcinoma (PDAC) is notable for its profuse desmoplastic stroma comprising activated fibroblasts, leukocytes and extracellular matrix components $[1,2]$. Studies utilizing in vitro assays and transplantation models have concluded that various stromal elements of the tumor microenvironment (TME) can enhance cancer cell proliferation and invasion [3-7]. Various stromal cells may also contribute to immunosuppression, further supporting tumor survival and growth. Together, these observations have led to the paradigm that tumor stroma 
functions to support and promote cancer growth [8]. Based on this paradigm, the concept of "anti-stromal" therapy has emerged as a promising, albeit unproven, therapeutic option. In contrast, Rim et al. reported that some stromal constituents may act to restrain, rather than promote tumor progression [9]. Although the role of tumor stroma in PDAC is still controversial, it has been reported that interactions between cancer cells and stroma components through the action of secreted proteins could play crucial roles in PDAC progression.

Stable Isotope Labeling by Amino acid in Cell culture (SILAC) with click chemistry is a comprehensive, quantitative and sensitive tool for the analysis of secreted proteins even in the presence of serum [10]. Secreted proteins are labeled with an azido-containing amino acid allowing their capture from complex mixtures through click chemistry, thereby circumventing the need for extensive peptide fractionation. In addition, concomitant stable isotope labeling allows relative protein quantification by mass spectrometry.

The complement system is a central part of both the innate and acquired immune systems that serve as a first line of defense against pathogens and stressed host cells [11]. Complement-related proteins perform several immune and nonimmune functions in both circulatory blood and peritumoral tissues by mediating cell-cell and cell-stroma interactions. Recent studies have shown that complement is not exclusive to liver-derived intravascular and extravascular systems, and that its components can be secreted locally by tissue-resident and infiltrating cells [12]. Specifically, it has been highlighted that activation of the complement cascade in the TME may enhance tumor growth via multiple mechanisms [13].

Herein, we performed comparative secretome analyses between mouse pancreatic intraepithelial neoplasia (PanIN) cells and PDAC cells using SILAC with click chemistry to identify key secreted proteins. We focused on the clinical and molecular features of one identified secreted protein, complement factor B (CFB), in PDAC progression. We found that CFB regulates proliferation to prevent cellular senescence in PDAC cells. Our data may facilitate the development of novel PDAC treatment options.

\section{Materials and methods}

\subsection{Patients and human tissue samples}

PDAC tissues were obtained from 113 consecutive patients who underwent surgical resection in the Department of General Surgery, Chiba University Hospital, Japan, from January 2010 to December 2014 (the follow-up period is at least 5 years). All patients were diagnosed with primary PDAC histologically, and TNM classification was performed according to the UICC 8th edition. The study protocol (protocol \#2958) was approved the ethics committees of Chiba University, and written informed consent was obtained from each patient before surgery.

\subsection{Murine and human pancreatic cell lines and culture conditions}

Mouse primary pancreatic cells were cultured and maintained as described previously [14]. Murine PanIN (KC) cells were isolated from a mouse at a PanIN stage (Pdx1cre;LSL-Kras ${ }^{\mathrm{G} 12 \mathrm{D} /+}$ ) and PDAC (KPC) cell lines were established from the pancreas of a murine primary PDAC (Pdx1-cre;LSL-Kras ${ }^{\mathrm{G} 12 \mathrm{D} /+} ; \mathrm{p} 53^{\mathrm{R} 172 \mathrm{H} /+}$ ) provided by Dr. Sunil Hingorani [15]. The human PDAC cell lines BxPC-3, PANC-1, MIA PaCa-II, Capan-2, Capan-1, AsPC-1, CFPAC-1 and Hs766T were obtained from the American Type Culture Collection (ATCC, Manassas, VA, USA). BxPC-3, PANC-1 and MIA PaCa-II cells were cultured in Dulbecco's Modified Eagle Medium (DMEM; Sigma Aldrich, St Louis, MO, USA) supplemented with $10 \%$ fetal bovine serum (FBS) and antibiotics (1\% penicillin and streptomycin). CFPAC- 1 and Capan-2 cells were cultured in Iscove's Modified Dulbecco's Medium (IMDM; Thermo Fisher Scientific, Waltham, MA, USA) supplemented with $10 \%$ FBS and antibiotics, and AsPC-1 cells were cultured in RPMI-1640 medium (Thermo Fisher Scientific) supplemented with $10 \%$ FBS and antibiotics.

\subsection{SILAC with click chemistry}

For stable isotope labeling by amino acid in cell culture (SILAC) experiments, murine PanIN (KC) and PDAC (KPC) cells were maintained in SILAC medium comprising DMEM supplemented with $10 \%$ dialyzed FBS, Llysine and L-arginine or ${ }^{13} \mathrm{C}_{6}$-lysine and ${ }^{13} \mathrm{C}_{6}{ }^{15} \mathrm{~N}_{4}$-arginine (isotopic) at a concentration of $0.1 \mathrm{~g} / \mathrm{L}$ for light or heavy stable isotope labeling. Both light and heavy isotope-labeled cells, seeded in $10 \mathrm{~cm}$ culture dishes at $60-70 \%$ confluency growing in light and heavy isotope medium, were incubated for $30 \mathrm{~min}$ in methionine-free medium to deplete endogenous methionine followed by incubation with azidohomoalanine (AHA). AHA concentration and incubation time were optimized to $0.1 \mu \mathrm{M}$ and $12 \mathrm{~h}$, respectively. Collected media were centrifuged (8 min at $5000 \mathrm{~g}$ ), after which EDTA-free protease inhibitor was added and the mixture was frozen at $-80^{\circ} \mathrm{C}$. All assays were performed in independent biological duplicates with reversed SILAC labels. Newly synthesized proteins from concentrated media were enriched using a Click-iT Protein Enrichment Kit (Invitrogen C10416). 


\subsection{Protein identification and quantification by LC- MS/MS analysis}

Enriched proteins were digested by trypsin. Digested peptides were fractionated [16] with Stage-Tip [17] simultaneously with desalting. Each fractionated peptide was injected into a trap column $(\mathrm{C} 18,0.3 \times 5 \mathrm{~mm}$; DIONEX, CA, USA) and an analytical column $(\mathrm{C} 18,0.075 \times 120 \mathrm{~mm}$; Nikkyo Technos, Tokyo, Japan), which was attached to Ultimate 3000 (DIONEX). The flow rate of the mobile phase was $300 \mathrm{~nL} /$ $\min$. The solvent composition of the mobile phase was programmed to change in 180-min cycles with varying mixing ratios of solvent $\mathrm{A}(2 \% \mathrm{v} / \mathrm{v} \mathrm{CH} 3 \mathrm{CN}$ and $0.1 \% \mathrm{v} / \mathrm{v} \mathrm{HCOOH})$ to solvent $\mathrm{B}(90 \% \mathrm{v} / \mathrm{v} \mathrm{CH} 3 \mathrm{CN}$ and $0.1 \% \mathrm{v} / \mathrm{v} \mathrm{HCOOH})$. Purified peptides were introduced from HPLC to a LTQOrbitrap XL (Thermo Scientific, San Jose, CA, USA). One full scan cycle was applied (350-1200 m/z, resolution 60,000) followed by top three data-dependent collision induced dissociation (CID) MS/MS scans. Dynamic exclusion was applied as follows: 1 repeat count, 30 min repeat duration, 500 exclusion list sizes, and $180 \mathrm{~s}$ exclusion duration. Proteome Discoverer (version 1.3.0, Thermo Scientific, San Jose, CA, USA) was used to identify and quantify proteins from the mass, tandem mass spectra. Peptide mass data were matched by searching the UniProtKB mouse database (SwissProt 2017, 17,165 entries). Database search parameters were as follows: peptide mass tolerance, $2 \mathrm{ppm}$; fragment tolerance, $0.6 \mathrm{Da}$; enzyme was set to trypsin, allowing up to two missed cleavages; dynamic modifications, methionine oxidation, ${ }^{13} \mathrm{C}_{6},{ }^{15} \mathrm{~N}_{4}$-arginine and ${ }^{13} \mathrm{C}_{6}$-lysine; static modifications, cysteine carbamidomethylation. The minimum criteria of protein identification were applied with Xcorr vs. charge state filter, and the false discovery rate (FDR) was set to $<1 \%$. The FDR was estimated by searching against a randomized decoy database created by the Proteome Discoverer 1.3.0 program supplied by Thermo Scientific.

\subsection{Western blot analysis}

Extracted proteins were separated by electrophoresis on 5$12.5 \%$ XV PANTERA Gels (DRC, Tokyo, Japan) and transferred to membranes (PerkinElmer, Waltham, MA, USA). The membranes were blocked with $5 \%$ skim milk diluted in $0.1 \%$ Tris-buffed saline with Tween-20 (TBS-T) or PhosphoBLOCKER (Cell Biolabs, Inc., San Diego, CA, USA) at room temperature for $60 \mathrm{~min}$. Next, the membranes were incubated with primary antibodies overnight at $4{ }^{\circ} \mathrm{C}$, and incubated with secondary antibodies in blocking buffer. The membranes were subsequently incubated with enhanced chemiluminescence detection reagent (Amersham ${ }^{\mathrm{TM}}$ ECL ${ }^{\mathrm{TM}}$ Prime Western blotting detection reagent; GE Healthcare, Buckinghamshire, UK) and developed using a LAS-4000UV mini luminescent image analyzer (Fujifilm, Tokyo, Japan). The intensity of each band was quantified by densitometry using Image $\mathrm{J}$ software and used to calculate the relative protein level normalized to $\beta$-actin. A list of antibodies used is provided in Supplementary Information (Table S1).

\subsection{Short interfering RNA and reagents}

A short interfering RNA (siRNA) that specifically targets human $C F B$ mRNA (CFBsiRNA) to knockdown CFB expression was purchased from Ambion (Austin, TX, USA; CFBsiRNA; Cat \# 4,427,037), and a control siRNA (sicontrol) was obtained from Qiagen (Hilden, Germany, All Stars negative control siRNA). Three thousand cells were transfected with siRNAs ( $3 \mathrm{nmol} / \mathrm{L}$ final concentration) in Opti-MEM I Reduced Serum Medium (Thermo Fisher Scientific, Grand Island, NY, USA) using Lipofectamine ${ }^{\mathrm{TM}}$ RNAiMAX Transfection Reagent (Invitrogen, Carlsbad, CA, USA). At $72 \mathrm{~h}$ after siRNA transfection, knockdown efficiency was evaluated by Western blot analysis. The cells were used for the following assays $24 \mathrm{~h}$ after transfection.

\subsection{Proliferation assay}

Cell proliferation was evaluated using a Cell Counting Kit-8 (CCK-8) assay (Dojindo, Tokyo, Japan), according to the manufacturer's protocol. The absorbance value was measured at $450 \mathrm{~nm}$ to determine cell viability using a 96-well plate reader (iMark ${ }^{\mathrm{TM}}$ Microplate Reader; Bio-Rad Laboratories).

\subsection{Annexin V-PI apoptosis assay}

Apoptosis was evaluated using an Annexin V-FITC apoptosis detection kit (Nacalai Tesque, Kyoto, Japan) in conjunction with flow cytometry. Cells were treated for $12 \mathrm{~h}$,washed in cold PBS, resuspended in binding buffer, and stained with $5 \mu \mathrm{l}$ FITC-labeled Annexin V and $5 \mu$ propidium iodide (PI). As a positive control, Mitomycin C $(5 \mu \mathrm{g} / \mathrm{ml})$ (Nacalai Tesque, Kyoto, Japan) was used for the induction of early apoptotic cells. Cells were analyzed by flow cytometry using a CANTO II system (Beckton-Dickinson, CA, USA). All Data were analyzed using FlowJo v10.1r5 software (Ashland, OR, USA).

\subsection{SA- $\beta$-galactosidase staining}

Cellular senescence was evaluated using a Cellular Senescence Detection Kit SPiDER- $\beta$-Gal (Dojindo, Kumamoto, Japan) in conjunction with flow cytometry. Bafilomycin A1 working solution was added, after which the cells were incubated for $1 \mathrm{~h}$ in a $5 \% \mathrm{CO} 2$ incubator. Next, SPiDER- $\beta$-Gal working solution was added, and the cells were incubated for another $30 \mathrm{~min}$. Staining for 
senescence associated- $\beta$-galactosidase (SA- $\beta$-gal) was evaluated by fluorescence microscopy, and assessed by flow cytometry.

\subsection{Immunohistochemistry (IHC)}

Formalin-fixed paraffin-embedded tissue samples were cut into $4-\mu \mathrm{m}$-thick slices and deparaffinized. Antigens were activated by autoclaving the tissue slides in citric acid buffer $(0.01 \mathrm{~mol} / \mathrm{L}, \mathrm{pH} 6.0)$ at $120^{\circ} \mathrm{C}$ for $10 \mathrm{~min}$. The slides were blocked with hydrogen peroxide $\left(\mathrm{H}_{2} \mathrm{O}_{2}\right)$ diluted to $3 \%$ with methanol for $15 \mathrm{~min}$ to inactivate endogenous peroxidase. IHC was performed using the hyper-sensitive polymer method (Dako EnVision + kit; Glostrup, Denmark) for CFB according to the manufacturer's protocol. After protein blocking, the slides were incubated with anti-CFB polyclonal antibody (1:1000 dilution; Proteintech, Rosemont, IL, USA) overnight at $4{ }^{\circ} \mathrm{C}$. Counterstaining was performed with hematoxylin before dehydration, penetration and mounting. The staining intensities of CFB were evaluated independently by two investigators and a pathologist. The staining intensity of islets of Langerhans cells was used as an internal positive control. CFB staining scores were based on the extent and intensity of staining. Scores of the extent of staining were based on the percentage of positive stroma area $(0-25 \%, 1$; $26-75 \%, 2 ;>75 \%, 3)$. Scores of the intensity of staining were: no staining, 0 ; weak staining, 1 ; moderate staining, 2 ; strong staining, 3). Overall scores of each slide were calculated by the formula: overall score $=$ extent score $\times$ intensity score. A score of $<2$ was considered as Low expression and a score of 2 or more was considered as High expression. The staining patterns of CD8 or Foxp $3^{+}$Treg cells were scored by counting tumor stromal lymphocytes with positive staining in an average of 5 different high-power fields $(\times 400)$ and classified as above (High) and below (Low) the median (CD8; range: $2-48$, median: 16 , average: 16 , Foxp $3^{+}$Treg; range: 1-83, median: 13 , average: 16). A list of antibodies used is provided in Supplementary Information (Table S1).

\subsection{Immunofluorescence staining}

Antigens were activated and blocking was performed as indicated above. The primary and secondary antibodies used are listed in Supplementary Information. ProLong ${ }^{\text {TM }}$ Gold antifade reagent with DAPI (Invitrogen) was used for counter staining of nuclei.

\subsection{Statistical analysis}

Correlations between CFB expression and PDAC patient characteristics were evaluated by $\chi^{2}$ test, Mann-Whitney U test and Tukey's HSD test. Survival rates were calculated using Kaplan-Meier analysis and assessed by log-rank test.
Data were generated from in vitro experiments carried out at least three times independently, and analyzed by $\chi^{2}$ test, Tukey's HSD test and multivariate analysis of variance (ANOVA). $P$ values $<0.05$ were considered to be statistically significant. Values are expressed as the mean \pm standard error of the mean (SEM) or standard deviation (SD). The above statistical analyses were carried out using JMP® PRO 13 software (SAS Institute Inc., Cary, NC, USA).

\section{Results}

\subsection{Identification by comprehensive secretome analysis of complement factor B as an upregulated secreted protein in pancreatic cancer}

To identify key secreted proteins involved in PDAC progression, comparative analyses of proteins present in the culture medium of mouse PanIN and PDAC cells were performed using SILAC with click chemistry and labeling by AHA (Fig. 1a). In total, 413 proteins were identified as secreted proteins by liquid chromatography/mass spectrometry (LCMS/MS) (Table S2). Among them, 198 proteins were consistently identified and 77 proteins were found to exhibit highly correlated relative secretion levels between biological replicates $(\mathrm{R}=0.823 ; p<0.0001$; Fig. 1b). By defining 2 -fold constitutive change as a cutoff value of difference in secretion, we detected 13 proteins with higher secretion levels in PDAC cells (Fig. 1c). Among these 13 proteins (Table 1), we focused on complement factor $\mathrm{B}$ (CFB) for further analysis because it has recently been reported that activation of components of the complement cascade is closely associated with cancer progression [13]. We validated a stepwise upregulation in intrinsic cellular expression of CFB during PDAC progression (Fig. 1d).

\subsection{CFB is abundantly expressed in primary human PDAC tissues and cell lines}

To confirm CFB expression in PDAC, its expression in human PDAC tissues and cell lines was assessed by Western blotting. We found that CFB was highly expressed in primary tumor samples compared to adjacent normal pancreatic tissues (Fig. 2a). CFB was also found to be expressed in all human PDAC cell lines tested (Fig. 2b). To next explore the relationship between CFB expression and epithelial plasticity in PDAC cells, endogenous CFB expression was suppressed by siRNA. We found that CFB knockdown altered neither E-cadherin nor vimentin expression in PANC-1 or MIA PaCa-II cells (Supplementary Fig. 1). This finding suggests that intrinsic CFB expression is not involved in epithelial plasticity in PDAC cells. 
a
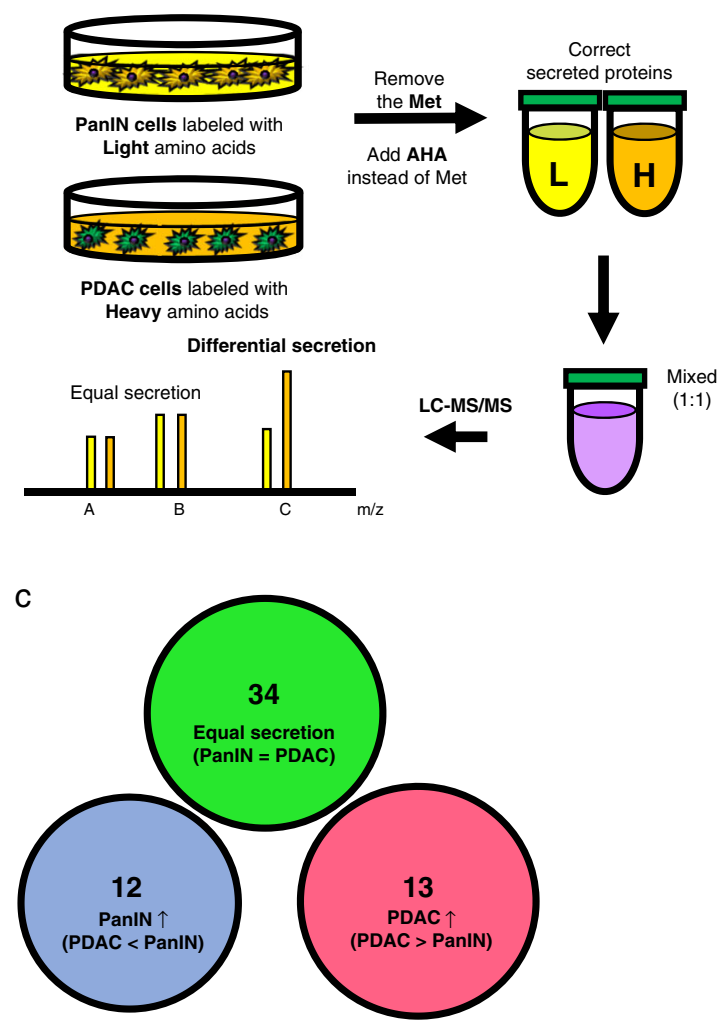

Fig. 1 Comprehensive and comparative analyses of secreted proteins using SILAC with click chemistry and LC-MS/MS. a Experimental flow for identification of target proteins in this study. PanIN, pancreatic intraepithelial neoplasia; PDAC, pancreatic ductal adenocarcinoma; AHA, azidohomoalanine. b Validation of differential expression of 77 identified proteins in biological replicates in two independent experiments. $\mathbf{c}$ Validation of proteins using 2-fold constitutive change as a cutoff value for differential secretion. Twelve proteins with 2 -fold

Table 1 List of identified secreted proteins by SILAC and clickchemistry

\begin{tabular}{lll}
\hline Identified secreted proteins & $\begin{array}{l}\text { Ratio } \\
\text { (replicate 1) }\end{array}$ & $\begin{array}{l}\text { Ratio } \\
\text { (replicate 2) }\end{array}$ \\
\hline DanJ homolog subfamily B member 9 & 10.5 & 3.61 \\
4F2 cell-surface antigen heavy chain & 10.2 & 4.63 \\
Complement factor B & 9.34 & 2.69 \\
Mesothelin & 8.40 & 3.59 \\
Cadherin-1 & 8.30 & 2.86 \\
Procollagen C-endopeptidase enhancer 1 & 7.80 & 7.83 \\
Semaphorin-3 C & 5.71 & 2.72 \\
Extracellular matrix protein 1 & 4.10 & 2.92 \\
Insulin-like growth factor-binding protein 3 & 3.22 & 2.15 \\
Metalloproteinase inhibitor 1 & 3.21 & 2.03 \\
Nidogen-1 & 2.81 & 2.46 \\
Glyceraldehyde-3-phosphate dehydrogenase & 2.65 & 5.86 \\
Growth-regulated alpha protein & 2.04 & 3.34
\end{tabular}

Ratio represents the ratio of secreted protein levels of PDAC cells to those of PanIN cells b

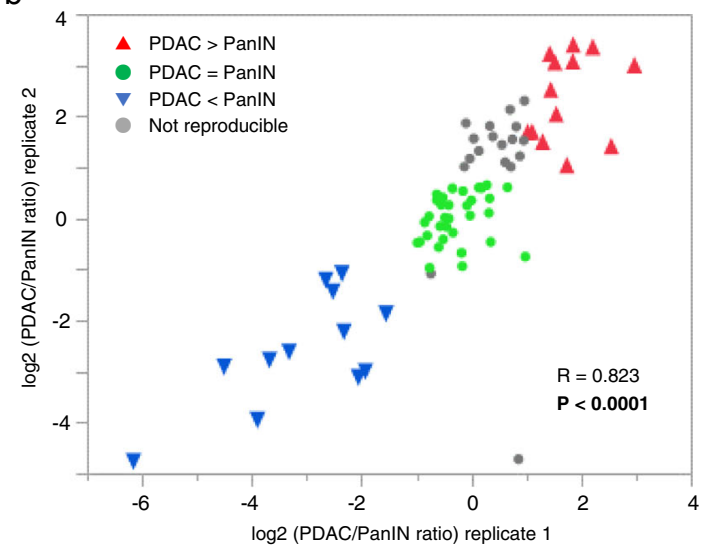

d

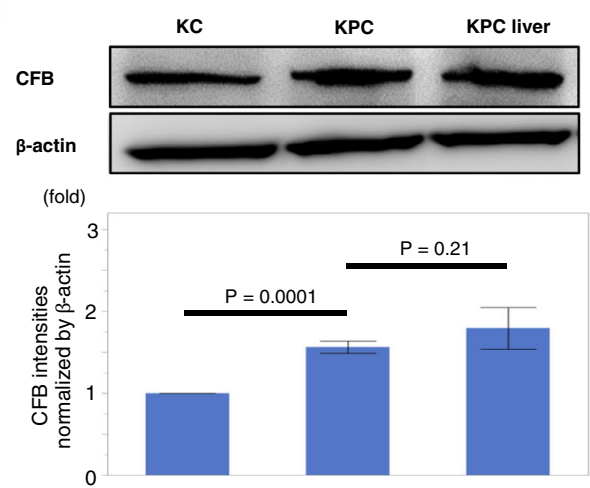

higher secretion levels in PanIN cells (blue), 34 proteins with comparable secretion levels (green) and 13 proteins with 2-fold higher secretion levels in PDAC cells (red). d Comparative analysis of endogenous CFB protein expression levels in established mouse cell lines derived from (PanIN) cells $(\mathrm{KC}), \mathrm{PDAC}$ in primary site (KPC), and its metastatic site in liver (KPCLiver) by Western blotting. Band intensities were normalized to $\beta$ actin. Experiments were performed in triplicates. Error bars represent standard deviation $(\mathrm{SD})$

\subsection{CFB knockdown dramatically decreases proliferation of PDAC cells}

Next, to assess the direct effect of CFB on PDAC cells, we determined whether CFB expression affects the proliferation of PDAC cells. Interestingly, we found that siRNA-mediated CFB knockdown resulted in dramatic decreases in the proliferation rates of both PANC-1 and MIA PaCa-II cells ( $p<0.0001$; Fig. 2 c). Subsequently, we found that the expression of proliferating cell nuclear antigen (PCNA), which is upregulated during the $\mathrm{S}$ phase of cell cycle and plays a role in DNA replication, was also repressed in CFB-knockdown PDAC cells (Fig. 2d). These results indicate that CFB regulates PDAC cell proliferation via cell cycle control. 


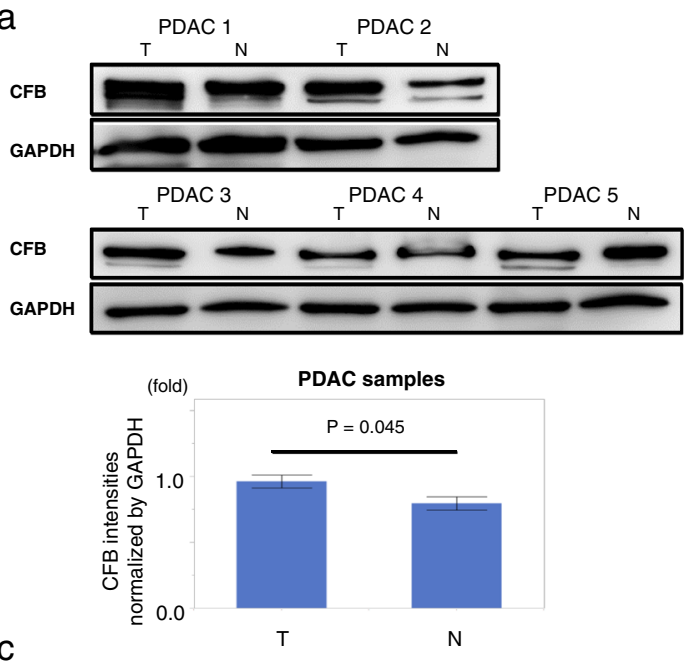

b

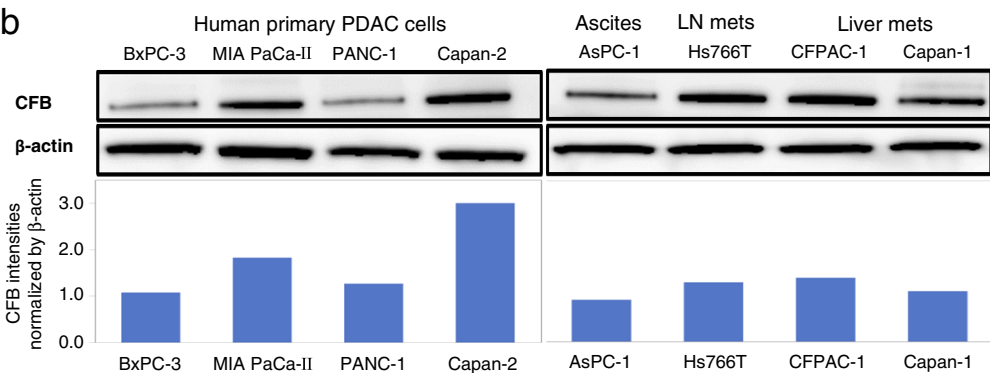

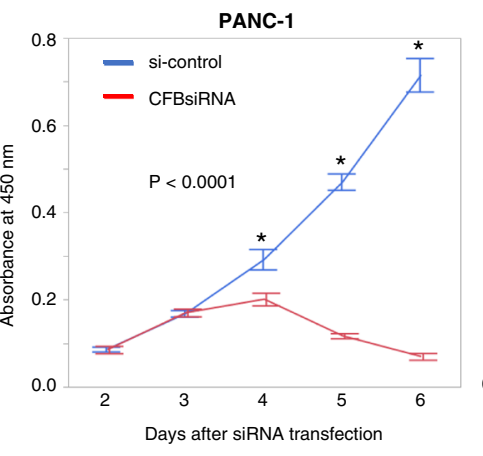

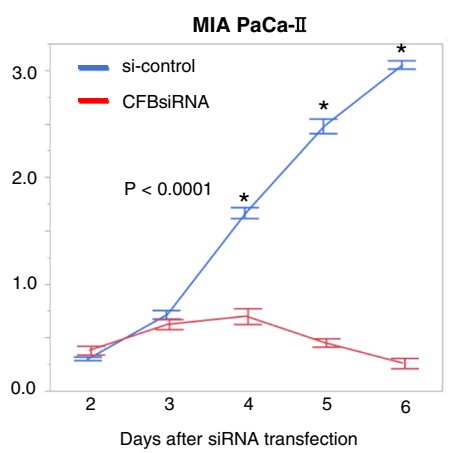

d
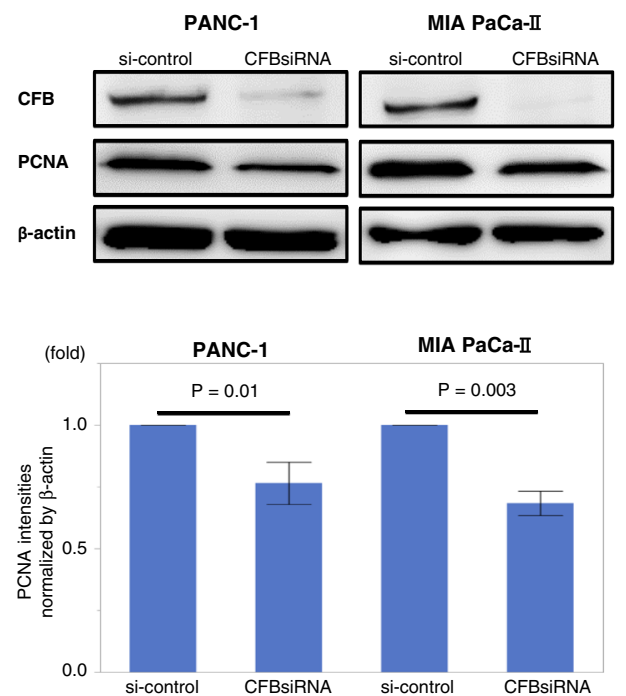

Fig. 2 Differential expression of CFB in different human PDAC tissues and PDAC cell lines. a Upper panel: CFB protein expression in resected PDAC tissues by Western blot analysis. Lower panel: comparative analysis of CFB expression between tumor tissues and adjacent normal pancreatic tissues. Band intensities were normalized to GAPDH. Error bars represent SD. T: tumor tissues, N: adjacent normal pancreatic tissues. b Upper panels: CFB expression in various human PDAC cell lines from primary PDACs (BxPC-3, MIA PaCa-II, PANC-1, Capan-2), metastatic ascites (AsPC-1), lymph node metastasis (Hs766T) and PDAC liver metastases (CFPAC-1, Capan-1) detected by Western blot analysis. Lower

\subsection{Apoptosis is not involved in proliferation suppression of CFB knockdown PDAC cells}

Apoptosis is one of the major phenomena of programmed cell death. Therefore, we first assessed whether apoptotic cell death is a canonical mechanism for inhibition of proliferation of CFB knockdown PDAC cells. We found that CFB knockdown did not increase the number of early apoptotic cells as demonstrated by annexin V/PI staining (Supplementary Fig. 2a-b). Additionally, we did not observe any increase in cleaved caspase-3 levels in CFB-knockdown cells (Supplementary Fig. 2c). These data indicate that the decreased cell proliferation observed in CFB knockdown PDAC cells is not likely to be due to apoptotic cell death. panels: comparative analysis of CFB expression among PDAC cell lines. Band intensities were normalized to $\beta$-actin. $\mathbf{c}$ CFB knockdown impairs cell proliferation in PDAC cells. Significantly decreased proliferation in CFB-knockdown PANC-1 and MIA PaCa-II cells $(p<0.0001$; MANOVA test). d Upper panel: PCNA expression evaluated in PANC1 and MIA PaCa-II cells treated with si-control and CFBsiRNA by Western blotting. Lower panel: comparative analysis between CFB expression and PCNA expression. Band intensities were normalized to $\beta$ actin. Error bars represent SD

\subsection{Loss of CFB induces senescence with p21 upregulation in PDAC cells}

Cellular senescence is characterized by an irreversible arrest in the G1 phase of the cell cycle, limiting the proliferation of primary human cells propagated in vitro. To explore whether intrinsic CFB expression is involved in the regulation of senescence, we performed SA- $\beta$-gal staining, one of the major hallmarks of cellular senescence. Remarkably, we found a significantly higher positive staining for SA- $\beta$-gal in CFB knockdown PDAC cells than in control cells (Fig. 3a). Also, a time-dependent increase in SA- $\beta$-gal positive staining was noted in cells treated with CFBsiRNA compared to si-control cells (Fig. 3b-c). We next assessed the expressions of pro- 


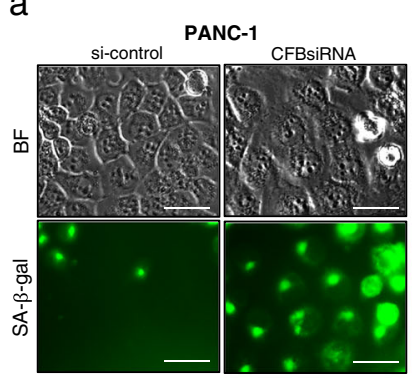

d

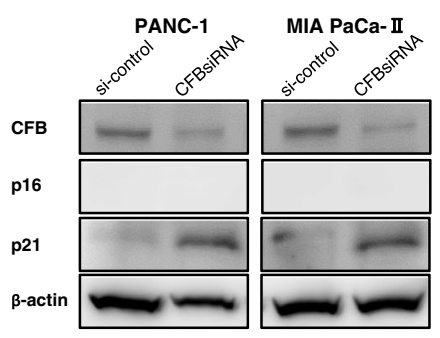

b

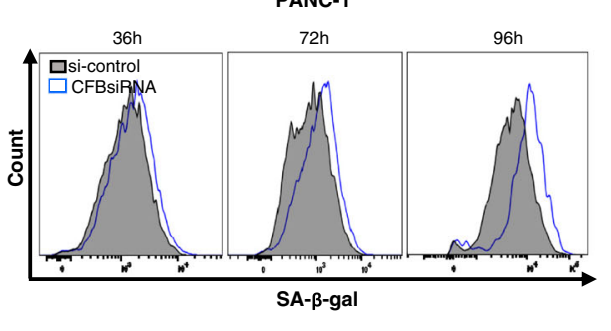

e

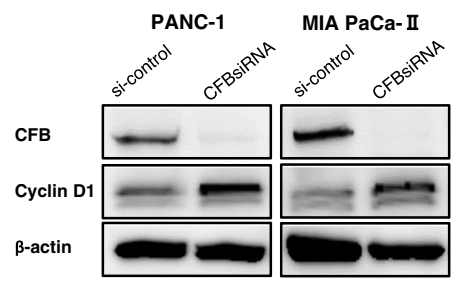

C

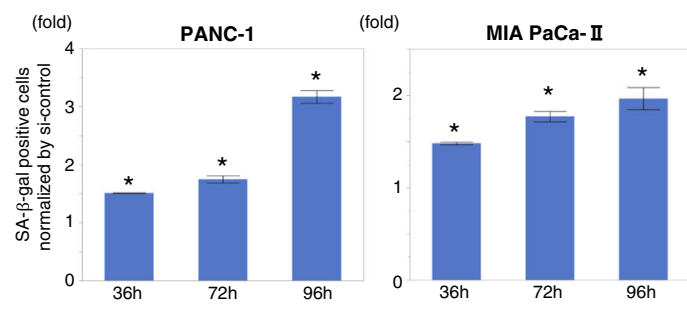

Fig. 3 CFB knockdown by CFBsiRNA induces cellular senescence in CFB knockdown PDAC cells. a Representative image of SA- $\beta$-gal staining of PANC-1 and MIA PaCa-II cells treated with si-control or CFBsiRNA. Upper panels: bright field pictures; Lower panels: immunofluorescence pictures. b, $\mathbf{c}$ Analysis of SA- $\beta$-gal staining by flow cytometry in PDAC cells treated with si-control or CFBsiRNA. b Overlay of SA- $\beta$-gal positive populations of PANC-1 cells treated with si-control or CFBsiRNA. c Time-dependent analysis of SA- $\beta$-gal positive cells.

senescence factors, p21 and p16, in CFB-knockdown cells. Consistent with the above staining results, CFB knockdown caused an increase in $\mathrm{p} 21$ protein abundance in PDAC cells (Fig. 3d). To elucidate the mechanism underlying cell cycle arrest induction by senescence, we next assessed cyclin D1 expression (Fig. 3e). Interestingly, we found that increased cyclin D1 expression was accompanied by activation of upstream targets of key mitogenic pathways, i.e., phosphorylated extracellular signal-regulated kinase (ERK) [18] and phosphorylated protein kinase B (Akt) [19], in CFB knockdown PDAC cells (Fig. 3f, Supplementary Fig. 3). Taken together, these findings unveil a novel cell autonomous mechanism by which loss of endogenous CFB expression fosters p21dependent cellular senescence in PDAC cells.

\subsection{High stromal CFB expression is associated with hematogenous recurrence and a poor prognosis after surgery in PDAC patients}

To next investigate the clinical significance of CFB expression, we assessed CFB expression in 113 resected human PDAC samples by IHC staining. We found that CFB was primarily expressed in the stroma surrounding the tumor and f

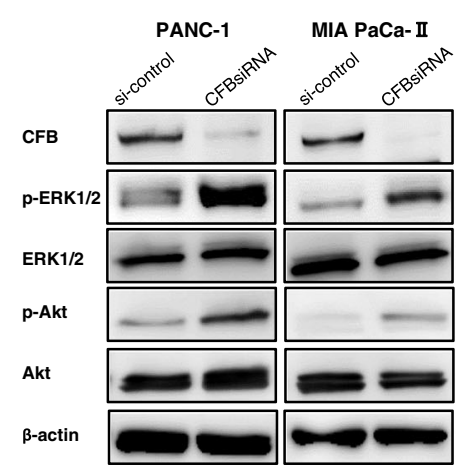

${ }^{*} p<0.0001$ compared with si-control. d Western blot analysis of $\mathrm{p} 16$ and $\mathrm{p} 21$ expression in PDAC cells treated with si-control or CFBsiRNA. e Western blot analysis of cyclinD1 expression in PDAC cells treated with si-control or CFBsiRNA. f Western blot analysis for key mitogenic signaling pathways in CFB knockdown PDAC cells. p-ERK and p-Akt expression in PDAC cells treated with si-control or CFBsiRNA. Results are represented as mean \pm SD. Each experiment was performed three times

in the cytoplasm of tumor cells (Fig. 4a). We measured CFB expression in both stroma and cytoplasm of tumor cells and found that among the 113 cases, 77 cases $(68 \%)$ were classified as high stromal CFB and 36 cases (32\%) as low stromal CFB, while 60 cases $(53 \%)$ were classified as high cytoplasmic CFB and 53 cases (47\%) as low cytoplasmic CFB. The respective staining patterns showed a positive correlation in PDAC tissues ( $p=0.036$; Fig. $4 \mathrm{~b}$ ). Considering the fact that CFB is secreted from PDAC cells, we focused on stromal CFB expression in evaluating clinical pathological features and outcomes. Interestingly, we found that the high stromal CFB group showed a significantly higher frequency of hematogenous recurrence ( $p=0.0083$; Table 2$)$, and shorter disease free ( $p=0.009$; Supplementary Fig. 4$)$ and overall survival $(p=0.007$; Fig. $4 c)$ compared to the low stromal CFB group. Upon multivariate analysis, we found that tumor size, venous invasion and stromal CFB expression served as independent markers for a poor prognosis of PDAC patients (Table 3). To validate these clinical data in an independent cohort, we evaluated CFB mRNA expression in a publicly available pancreatic ductal adenocarcinoma dataset of The Cancer Genome Atlas (TCGA-PAAD) [20]. The patients of the TCGAPAAD cohort were divided into two groups based on the same 
a

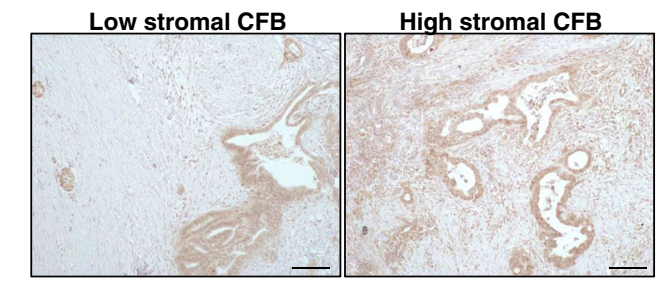

C

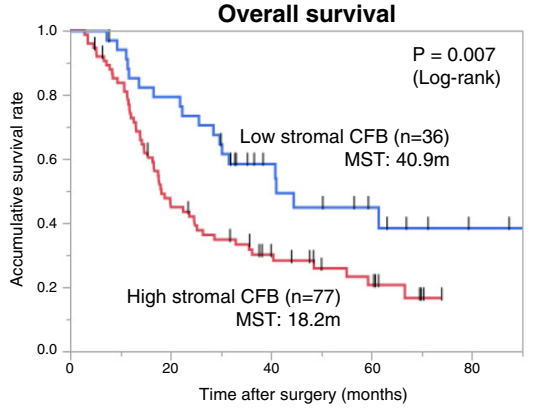

Fig. 4 IHC analyses of CFB expression in resected human PDAC samples. a The staining patterns of CFB in primary PDAC tissue were categorized into low stromal CFB expression (left panel) or high stromal CFB expression (right panel) based on the intensity criterion (see Materials and Methods) $(n=113)$. Original magnification 200x. b Correlation of CFB expression between stroma and cytoplasm of cancer cells in human PDAC tissues. c, d Kaplan-Meier analyses of overall survival of patients with PDAC based on stromal CFB expression in b

\section{d}
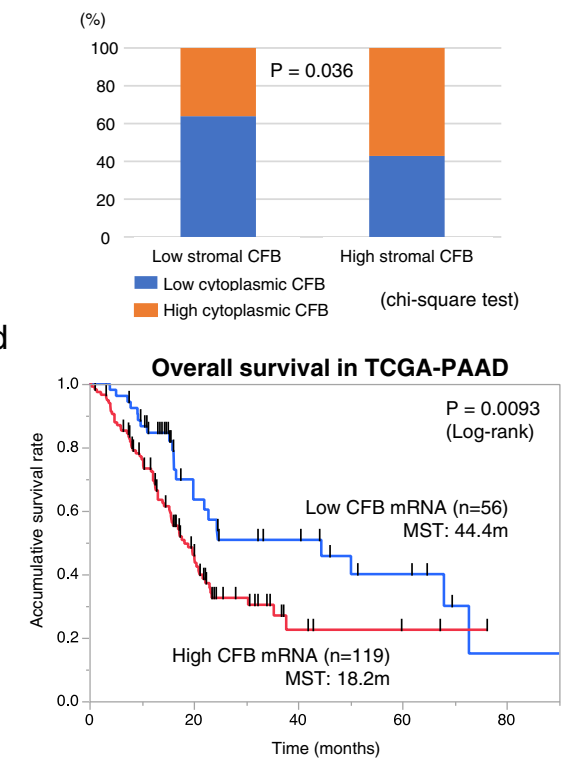

the cohort of this study $\mathbf{c}$ and CFB mRNA expression in the TCGAPAAD dataset d. c Patients in the high stromal CFB group presented significantly shorter overall survival times than patients in the low stromal CFB group after curative surgery ( $p=0.007$ : log-rank test). $\mathbf{d}$ Patients in the high CFB mRNA group presented significantly shorter overall survival times than patients in the low CFB mRNA group in the TCGAPAAD dataset $(p=0.0093$ : $\log$-rank test). $P$ values are indicated in the respective tables

Table 2 Correlation between stromal CFB expression and clinico-pathological features

\begin{tabular}{|c|c|c|c|}
\hline & High stromal CFB $(n=77)$ & Low stromal CFB $(n=36)$ & $P$ value \\
\hline Sex (Male/Female) & $44 / 33$ & $20 / 16$ & 0.87 \\
\hline Age (y.o. median: range) & $67(35-82)$ & $65(38-81)$ & 0.25 \\
\hline Preoperative CA19-9 level (U/ml median: range) & $245.5(0.1-6530)$ & $73.6(0.1-6380)$ & 0.36 \\
\hline NLR (median: range) & $2.32(0.86-7.60)$ & $2.05(0.93-5.75)$ & 0.31 \\
\hline LMR (median: range) & $3.75(1.04-9.76)$ & $4.85(1.57-8.60)$ & 0.087 \\
\hline PLR (median: range) & $172(42-942)$ & $140(82-325)$ & $0.020 *$ \\
\hline Preoperative treatment $(+/-)$ & $36 / 41$ & $15 / 21$ & 0.61 \\
\hline Histological grade (poorly/others) & $7 / 70$ & $7 / 29$ & 0.17 \\
\hline Tumor size (mm median: range) & $32(12-79)$ & $30(15-70)$ & 0.26 \\
\hline Portal vein invasion $(+/-)$ & $39 / 37$ & $14 / 22$ & 0.22 \\
\hline Arterial invasion $(+/-)$ & $11 / 66$ & $3 / 33$ & 0.34 \\
\hline Lymphatic vessel invasion $(0,1 / 2,3)$ & $17 / 60$ & $15 / 21$ & $0.034 *$ \\
\hline Blood vessel invasion $(0,1 / 2,3)$ & $33 / 44$ & $14 / 22$ & 0.94 \\
\hline UICC-stage (I,II/III,IV) & $33 / 44$ & $27 / 9$ & $0.0012 *$ \\
\hline T-stage $(\mathrm{T} 1,2 / \mathrm{T} 3,4)$ & $52 / 25$ & $30 / 6$ & 0.07 \\
\hline N-stage (N0/N1,2) & $19 / 58$ & $12 / 24$ & 0.34 \\
\hline M-stage (M0/M1) & $71 / 6$ & $35 / 1$ & 0.17 \\
\hline Resectability (R0/R1,2) & $34 / 43$ & $11 / 25$ & 0.16 \\
\hline Adjuvant chemotherapy & $66 / 11$ & $29 / 7$ & 0.49 \\
\hline Local recurrence $(+/-)$ & $28 / 49$ & $14 / 22$ & 0.80 \\
\hline Hematogenous recurrence $(+/-)$ & $32 / 45$ & $7 / 29$ & $0.018 *$ \\
\hline Lymph node recurrence (+/-) & $9 / 68$ & $3 / 33$ & 0.92 \\
\hline
\end{tabular}

*: significant value. NLR: neutrophil to lymphocyte ratio. LMR: lymphocyte to monocyte ratio. PLR: platelet to lymphocyte ratio 
Table 3 Univariate and multivariate analyses by Cox proportional hazard model

\begin{tabular}{|c|c|c|c|c|}
\hline & \multicolumn{2}{|l|}{ Univariate analysis } & \multicolumn{2}{|c|}{ Multivariate analysis } \\
\hline & $\mathrm{HR}(95 \% \mathrm{CI})$ & $P$ value & HR $(95 \% \mathrm{CI})$ & $P$ value \\
\hline CA19-9 (U/ml) $(\geqq 250 /<250)$ & $1.68(1.05-2.67)$ & 0.029 & $1.43(0.87-2.37)$ & 0.16 \\
\hline Tumor size $(\mathrm{mm})(\geqq 30 /<30)$ & $1.83(1.16-2.92)$ & 0.010 & $1.65(1.01-2.71)$ & 0.047 \\
\hline ly $(0,1 / 2,3)$ & $0.47(0.26-0.80)$ & 0.004 & $0.98(0.50-1.88)$ & 0.96 \\
\hline $\mathrm{v}(0,1 / 2,3)$ & $0.35(0.22-0.56)$ & $<0.001$ & $0.32(0.18-0.57)$ & $<0.001$ \\
\hline Lymph node metastasis $(+/-)$ & $2.04(1.20-3.63)$ & 0.007 & $1.35(0.76-2.51)$ & 0.32 \\
\hline Stromal CFB expression (high/low) & $1.89(1.15-3.87)$ & 0.005 & $1.98(1.17-3.47)$ & 0.012 \\
\hline
\end{tabular}

percentage as in our cohort, (high CFB mRNA (119/175: $68 \%$ ) and low CFB mRNA (56/175: $32 \%)$ ). Similar to the above results, analysis of the TCGA-PAAD dataset revealed that the high CFB mRNA group again had a significantly worse prognosis compared to the low CFB mRNA group ( $p=0.0093$; Fig. 4d). These results implicate that high stromal $\mathrm{CFB}$ expression is associated with hematogenous recurrence and a poor prognosis in patients with PDAC after surgery.

\subsection{Immunosuppressive cells accumulate in CFB-rich stroma in PDAC tissues}

We found that intrinsic and extrinsic CFB expression in PDAC tissues, and its stromal expression, were closely correlated with poor prognosis. Senescence is one of the physiological stress response programs characterized by loss of proliferative capacity, and it facilitates the recruitment of tumor infiltrating lymphocytes to the TME. Therefore, we hypothesized that the anti-senescence function of CFB may stimulate a pro-tumoral immune response by establishing an immunosuppressive TME. We assessed accumulation of tumorinfiltrating $\mathrm{CD}^{+} \mathrm{T}$ cells $\left(\mathrm{CD} 8^{+}\right.$cells), which is one of the most crucial reactions of the host immune response against tumor cells. The number of $\mathrm{CD} 8^{+}$cells at the invasive front of the tumor was analyzed in resected human PDAC tissues by IHC (Fig. 5a). After division into high and low $\mathrm{CD} 8^{+}$ groups, we found that the high $\mathrm{CD} 8^{+}$group showed a better prognosis compared to the low $\mathrm{CD}^{+}$group $(p=0.015$; Supplementary Fig. 5a). Subsequent Kaplan-Meier analysis revealed that patients with low stromal CFB expression exhibited a significantly longer overall survival time than those with high stromal CFB expression in the high $\mathrm{CD} 8^{+}$group ( $p=0.013$; Fig. 5 b). Of note, even in the high $\mathrm{CD} 8^{+}$group, the survival curve of the high stromal CFB group was almost equal to that of the low $\mathrm{CD} 8^{+}$group (Fig. $5 \mathrm{~b}-\mathrm{c}$ ). These results were also validated through $\mathrm{KM}$ plotter analysis, which is an online database using gene expression data and survival information of cancer patients downloaded from the Gene Expression Omnibus (GEO), the European Genomephenome Archive (EGA) and TCGA (Supplementary Fig. 5b-c) [21]. The data obtained suggest that high stromal
CFB expression impacts the poor survival against T-cell mediated antitumor immunogenicity in PDAC patients.

We finally examined correlations between CFB expression and the presence of pro-tumoral immune cells, promoting cancer cell spread and distant metastasis in human PDAC tissues. Immunofluorescence CFB staining and staining for immunosuppressive cell markers revealed their co-localization and dynamic enrichment of regulatory T cells (Tregs) (Fig. 5d-h), myeloid-derived suppressor cells (MDSCs) (Fig. 5i-l) and tumor-associated macrophages (TAMs) (Fig. 5m-p) in stroma surrounding the cancer cells in PDAC tissues. Recent research revealed that $\mathrm{CD}^{+}$Tregs accumulate in the TME and suppress antitumor immunity, thus promoting immune evasion and cancer progression $[22,23]$. We assessed whether the high stromal CFB group is associated with the high $\mathrm{CD}^{+} /$high Tregs PDAC group. The numbers of Foxp $3^{+}$cells surrounding the tumor were analyzed by IHC to divide the PDAC tissues into high and low Foxp $3^{+}$groups (Fig. 6a). We found that the percentage of high $\mathrm{CD}^{+} / \mathrm{Foxp}^{+}$Tregs in the high stromal CFB group was significantly higher than that in the low stromal CFB group $(p=$ 0.044; Fig. 6b). These data indicate that this phenotype is associated with immunological tumor promotion in the TME facilitating PDAC progression and imposing a poor clinical prognosis.

\section{Discussion}

We identified CFB as an upregulated secreted protein in PDAC cells by comprehensive secretome analysis. Our in vitro data indicate that $\mathrm{CFB}$ plays a functional role in PDAC cancer cell survival by preventing cellular senescence via 21 expression regulation. IHC analyses revealed that high stromal CFB expression is associated with an unfavorable prognosis and correlates with recurrence and hematogenous dissemination after curative resection (Fig. 6c).

The central role of complement in inflammatory circuits is reflected by its involvement in acute and chronic inflammatory disorders with prominent complement imbalance [12]. It can be activated through three major pathways, i.e., the classic, lectin and alternative pathways [24]. Recent discoveries have 

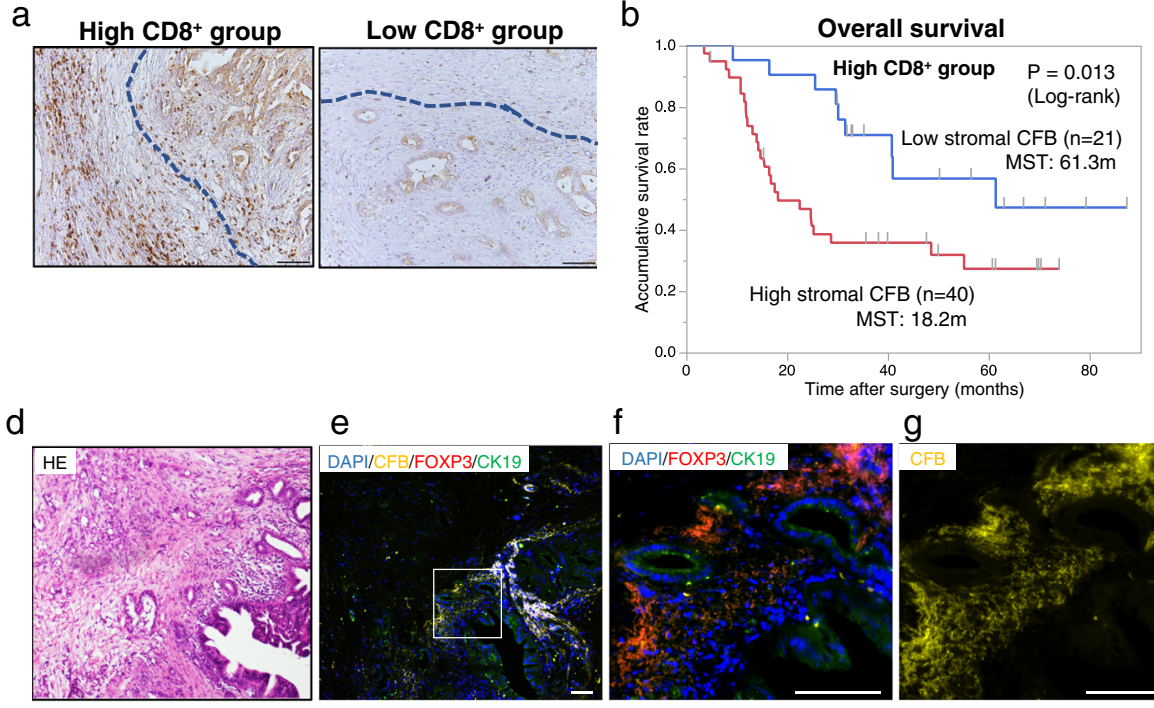

e
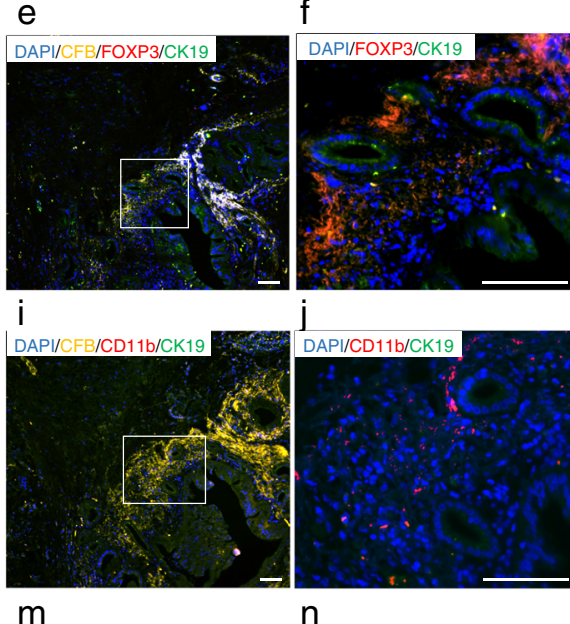

$\mathrm{m}$
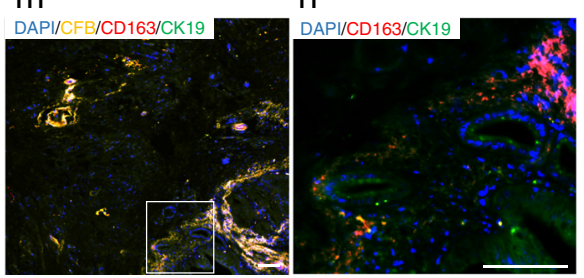

Fig. 5 Correlations between immunocompetent or immunosuppressive cells and CFB expression in human PDAC tissues. a The staining patterns of $\mathrm{CD}^{+} \mathrm{T}$ cells in primary PDAC tissues were categorized into high $\mathrm{CD}^{+}$expression (upper panel) or low $\mathrm{CD}^{+}$expression (lower panel). The blue dotted line indicates the area of the invasive tumor front where $\mathrm{CD}^{+}$cells were counted. Original magnification 40x. b, c Kaplan-Meier analyses of overall survival of PDAC patients based on CFB expression in high and low $\mathrm{CD} 8^{+} \mathrm{T}$-cell groups. b Patients with high stromal CFB presented a significantly shorter overall survival time $(p=0.013$ : log-rank test) than patients with low stromal CFB in the high $\mathrm{CD} 8^{+}$group. $\mathbf{c}$ Both patients with high and low stromal CFB showed a poor prognosis in the

revealed that complement effectors can also be generated intracellularly, which leads to its activation locally, independent of the plasmatic cascade [25]. CFB is known to play an important role in the alternative pathway of the complement cascade. CFB binds to $\mathrm{C} 3\left(\mathrm{H}_{2} \mathrm{O}\right)$ or $\mathrm{C} 3 \mathrm{~b}$, and is cleaved by complement factor $\mathrm{D}$ into fragments $\mathrm{Ba}$ and $\mathrm{Bb}$ [26], which have a stimulatory effect on the proliferation of activated human B cells [27]. Complement functions vary across cancer types as it can promote or suppress tumor growth depending on the context. A previous report indicated that $\mathrm{CFB}$ is highly expressed in PDAC cells grown in conditioned media [28]. In this study, we demonstrated that the secreted CFB protein abundance in

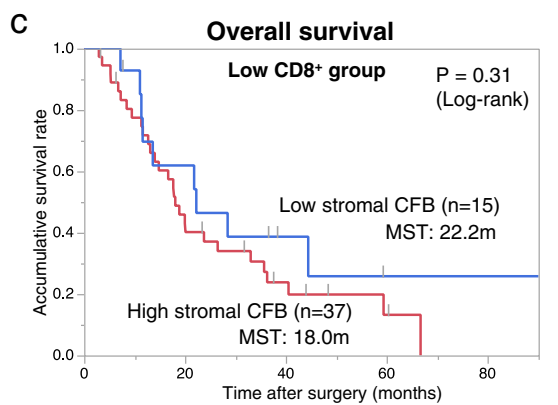

g

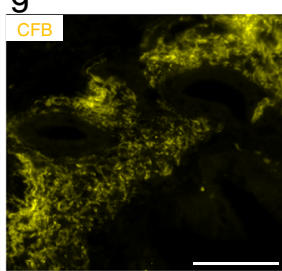

$\mathrm{k}$

$\mathrm{h}$

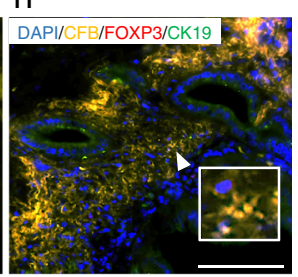

I
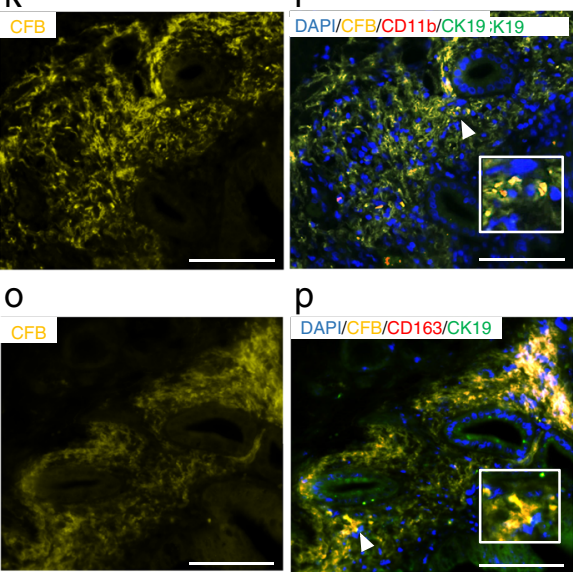

$p$

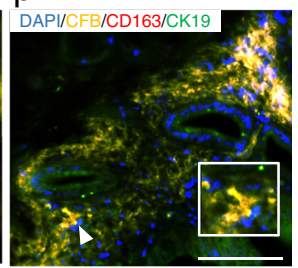

low $\mathrm{CD}^{+}$group. d-p Immunofluorescence analysis of immune cell markers, Foxp3 (Tregs), CD11b (MDSCs), and CD163 (TAMs) in human PDAC tissues. d Hematoxylin and eosin (H\&E) staining. e-h, $\mathbf{i}-\mathbf{l}$ and m-p Quadruple immunofluorescence staining for CK-19 (green), CFB (yellow), Foxp3/CD11b/CD163 (red) and DAPI (blue). Boxed regions highlight where stromal CFB is co-expressed with immunosuppressive cells, Tregs, MDSCs and TAMs in the TME of primary PDAC tissues. White arrowheads indicate representative regions where enrichment of immunosuppressive cells was observed in the CFB expressing stroma. Magnification 100x for (e, I, and m). Bar, $50 \mu \mathrm{m}$

PDAC cells is higher than that in PanIN cells. IHC staining clearly showed high CFB expression in both cancer cells and stroma of resected human PDAC tissues. Notably, we found that stromal CFB expression in human PDAC was significantly associated with early recurrence with hematogenous dissemination. Taken together, these finding implicate that secreted CFB may contribute to PDAC progression.

Cell proliferation with an epithelial characteristic is one of the most fundamental traits for metastatic colonization [8]. Recent evidence strongly suggests that components of the complement cascade function in cancer cell proliferation and/or survival. In ovarian cancer cells complement activation products $\mathrm{C} 3 \mathrm{a}$, and 
Fig. 6 Correlation of CFB expression and the presence of $\mathrm{CD} 8^{+} / \mathrm{Foxp}^{+}$Treg cells in resected PDAC tissues. a Black arrows show Foxp $3^{+}$Tregs in stroma surrounding pancreatic tumors. Original magnification 200x. b Correlation of CFB expression and $\mathrm{CD} 8^{+} / \mathrm{Foxp}^{+}$ Tregs in the TME of human PDAC tissues $(p=0.044$, chisquare test). c Scheme of autonomous and non-autonomous $\mathrm{CFB}$ functions in PDAC cells and the tumor microenvironment a

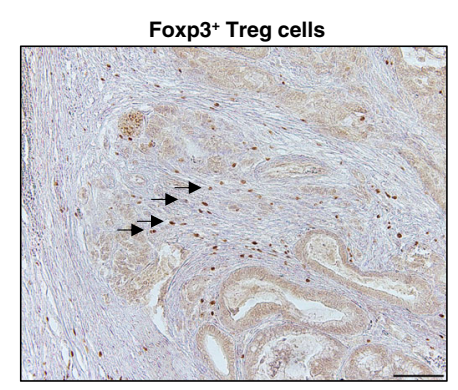

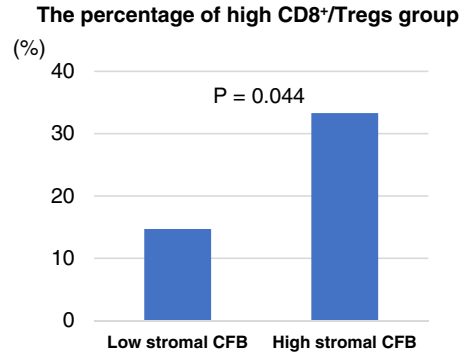

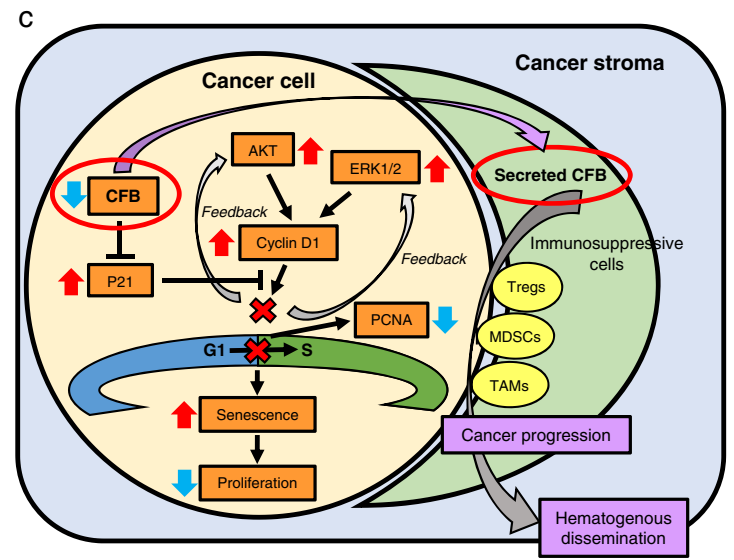

(chi-square test)

subsequently C5a, activate their receptors, resulting in increased proliferation via a direct autocrine effect [29]. It has also been shown that CFB knockdown results in a significant decrease in proliferation in cutaneous squamous cell carcinoma [30]. Consistent with previous findings, we here report that attenuation of endogenous CFB expression decreases PDAC cell proliferation through a novel mechanism where loss of intrinsic CFB leads to cellular senescence by cell cycle arrest at the G1 phase. We also show that CFB knockdown induces senescence in a manner dependent on p21 instead of p16. Elevated cyclin D1 levels are universal markers of senescence. Indeed, despite the activation of mitogenic signaling pathways involving phosphorylation of ERK and Akt [31], we found that PDAC cells with suppressed CFB expression cannot activate cyclin D1 and fail to progress into the $\mathrm{S}$ phase. In terms of clinical application, therapy-induced senescence is a well-known response to cancer therapy which has long been considered to be related to a favorable outcome and to be a basis for the development of novel therapies that induce a cytostatic response [32]. Indeed, CDK4/ 6 inhibition is a hot topic and anticipated to be a therapeutic option for various cancers [31]. Conversely, Milanovic et al. recently suggested that senescence is associated with complex cellular reprogramming that may eventually promote cancer stemness and give rise to a more aggressive cancer phenotype [33]. Further experiments aimed at the regulation of senescence by CFB may underscore the context-dependent effects of senescence, including the potential involvement of the senescenceassociated secretory phenotype (SASP) in cancer progression.
The TME is thought to highly affect cancer growth and spread, thereby impacting the clinical outcome of cancer patients. The majority of PDACs display highly immunosuppressive features with a TME rich in Tregs, MDSCs and TAMs, indicating "immuno-escape" for evading the host immune response [34]. Imbalanced activation of complement in the TME triggers the release of immunosuppressive cytokines, not only by cancer cells but also by Tregs and MDSCs which inhibit anti-tumor $\mathrm{CD}^{+}$T-cell responses. A recent study has provided evidence that local complement activation of $\mathrm{C} 3 \mathrm{a}$ and $\mathrm{C} 5 \mathrm{a}$ in the TME results in an immunosuppressive response to melanoma through the recruitment of MDSCs and inhibition of $\mathrm{CD}^{+}$ tumor infiltrating lymphocyte function [35]. Since CFB plays a crucial role in activation of the $\mathrm{C} 3-\mathrm{C} 5$ cascade in the alternative pathway, we hypothesized that CFB may be governed by PDAC cancer cells and act on the immunosuppressive response orchestrated by Tregs, MDSCs and TAMs in the TME. In line with this idea, we found that CFB co-localizes with tumor infiltrating immunosuppressive cells, resulting in cancer progression despite the presence of $\mathrm{CD}^{+}$tumor infiltrating lymphocytes in the TME of PDAC tissues. We also found that high stromal CFB expression showed a positive correlation with high $\mathrm{CD}^{+} /$Foxp $^{+}$Treg populations in PDAC tissues. Very recently, Gadwa et al. reported that depletion of Tregs reversed tumor growth, and that combination of Treg depletion and $\mathrm{C} 3 \mathrm{a}$ and $\mathrm{C} 5 \mathrm{a}$ receptor inhibition decreased tumor growth in head and neck cancer [36]. These results implicate CFB as a putative therapeutic target combined with immunomodulation therapy. 
Collectively, our results suggest that CFB secreted from tumor cells leads to a bypass of senescence and fosters cooperation between tumor cells and pro-tumoral immune cells in favor of PDAC progression.

We also observed a significant correlation between CFB expression and hematogenous recurrence in resected PDAC tissue samples. Supporting this observation, a recent study indicated that a molecular signature comprising eight degradomerelated genes including CFB can be used to discriminate patients at risk of distant metastasis [37]. Related to clinical application, a recent report described the identification of CFB as a novel serologic biomarker for PDAC diagnosis using an integrated proteomic analysis. CFB showed a distinctly higher specificity than CA19-9 for PDAC against other types of digestive cancers and in discriminating PDAC patients from nonPDAC patients [38]. Furthermore, consistent with our findings, Kim et al. recently demonstrated that high CFB expression in plasma of PDAC patients is highly associated with a poor prognosis with early recurrence after pancreatectomy [39]. Thus, CFB may serve not only as a therapeutic target, but also as a diagnostic and prognostic biomarker for PDAC.

In conclusion, we found that endogenous $\mathrm{CFB}$ regulates p21-dependent cellular senescence and that its stromal expression is associated with a poor prognosis in PDAC. These findings provide novel insight into a context-dependent role of complement in PDAC progression. A limitation of our current study is that the role of CFB was not investigated in an in vivo model. Further studies are warranted to examine the functional role of intrinsic and extrinsic CFB expression in PDAC progression, and to determine whether CFB may serve as a promising in vivo therapeutic target for PDAC.

Supplementary Information The online version contains supplementary material available at https://doi.org/10.1007/s13402-021-00614-z.

Acknowledgements The authors would like to thank Dr. Naoko Yoneura, Dr. Kensuke Suzuki, and Dr. Satoshi Tomizawa (Department of General Surgery, Chiba University, Japan) for their technical support in the experiments.

Author contributions RS, ST, MS, MT, and MO designed the study; RS, MS, MT, YM and KS performed the research; ST MS and MT supervised the experiments; RS, MS, HY, KF, TT, ShK, SaK, KS, SM, FN and MM discussed and analyzed the data; and RS and ST wrote the manuscript. All authors read and approved the final manuscript.

Funding This study was supported by a Grant-in-Aid for Scientific Research (KAKENHI): "KIBAN" B: 19H03725 (ST, HY, SK, MO), Challenge Exploratory Research: 16K15607 (ST, HY, MM), "KIBAN" C: 18K08671 (HY, ST, MO), "KIBAN" B: $17 \mathrm{H} 04287$ (MM, ST, HY, MO), and "KIBAN" C: 19K09113 (MO, ST, SaK). This study was also supported by Denka Co., Ltd. (ST, KS, MO) and the Japanese Foundation for Multidisciplinary Treatment of Cancer (ST).

Data availability All data generated or analyzed in this study are included in this article and its supplementary information files.

\section{Declarations}

Ethics approval and consent to participate The study protocol (protocol \#2958) was approved the ethics committees of Chiba University, and written informed consent was obtained from each patient before surgery.

Consent for publication Not applicable.

Conflict of interest ST, KS, and MO report receiving grants for this study from Denka Co., Ltd. No potential conflicts of interest were disclosed by the other authors.

Abbreviations AHA, azidohomoalanine; Akt, protein kinase B; CFB, complement factor B; ERK, extracellular signal-regulated kinase; LCMS/MS, liquid chromatography-mass spectrometry; MDSCs, myeloidderived suppressor cells; PanIN, pancreatic intraepithelial neoplasia; PDAC, pancreatic ductal adenocarcinoma; SA- $\beta$-gal, senescenceassociated- $\beta$-galactosidase; Tregs, regulatory T cells; SASP, senescence-associated secretory phenotype; SILAC, stable isotope labeling by amino acid in cell culture; siRNA, short interfering RNA; TAMs, tumor-associated macrophages; TME, tumor microenvironment

Open Access This article is licensed under a Creative Commons Attribution 4.0 International License, which permits use, sharing, adaptation, distribution and reproduction in any medium or format, as long as you give appropriate credit to the original author(s) and the source, provide a link to the Creative Commons licence, and indicate if changes were made. The images or other third party material in this article are included in the article's Creative Commons licence, unless indicated otherwise in a credit line to the material. If material is not included in the article's Creative Commons licence and your intended use is not permitted by statutory regulation or exceeds the permitted use, you will need to obtain permission directly from the copyright holder. To view a copy of this licence, visit http://creativecommons.org/licenses/by/4.0/.

\section{References}

1. K.P. Olive, M.A. Jacobetz, C.J. Davidson, A. Gopinathan, D. McIntyre, D. Honess, B. Madhu, M.A. Goldgraben, M.E. Caldwell, D. Allard, K.K. Frese, G. DeNicola, C. Feig, C. Combs, S.P. Winter, H. Ireland-Zecchini, S. Reichelt, W.J. Howat, A. Chang, M. Dhara, L. Wang, F. Ruckert, R. Grutzmann, C. Pilarsky, K. Izeradjene, S.R. Hingorani, P. Huang, S.E. Davies, W. Plunkett, M. Egorin, R.H. Hruban, N. Whitebread, K. McGovern, J. Adams, C. Iacobuzio-Donahue, J. Griffiths, D.A. Tuveson, Inhibition of Hedgehog signaling enhances delivery of chemotherapy in a mouse model of pancreatic cancer. Science 324, 1457-1461 (2009)

2. J.W. Theunissen, F.J. de Sauvage, Paracrine Hedgehog signaling in cancer. Cancer Res. 69, 6007-6010 (2009)

3. R.F. Hwang, T. Moore, T. Arumugam, V. Ramachandran, K.D. Amos, A. Rivera, B. Ji, D.B. Evans, C.D. Logsdon, Cancer- 
associated stromal fibroblasts promote pancreatic tumor progression. Cancer Res. 68, 918-926 (2008)

4. N. Ikenaga, K. Ohuchida, K. Mizumoto, L. Cui, T. Kayashima, K. Morimatsu, T. Moriyama, K. Nakata, H. Fujita, M. Tanaka, CD10 + pancreatic stellate cells enhance the progression of pancreatic cancer. Gastroenterology 139, 1041-1051 (2010)

5. E. Lonardo, J. Frias-Aldeguer, P.C. Hermann, C. Heeschen, Pancreatic stellate cells form a niche for cancer stem cells and promote their self-renewal and invasiveness. Cell Cycle 11, 1282-1290 (2012)

6. A. Vonlaufen, P.A. Phillips, Z. Xu, D. Goldstein, R.C. Pirola, J.S. Wilson, M.V. Apte, Pancreatic stellate cells and pancreatic cancer cells: an unholy alliance. Cancer Res. 68, 7707-7710 (2008)

7. Z. Xu, A. Vonlaufen, P.A. Phillips, E. Fiala-Beer, X. Zhang, L. Yang, A.V. Biankin, D. Goldstein, R.C. Pirola, J.S. Wilson, M.V. Apte, Role of pancreatic stellate cells in pancreatic cancer metastasis. Am. J. Pathol. 177, 2585-2596 (2010)

8. D. Hanahan, R.A. Weinberg, Hallmarks of cancer: the next generation. Cell 144, 646-674 (2011)

9. A.D. Rhim, P.E. Oberstein, D.H. Thomas, E.T. Mirek, C.F. Palermo, S.A. Sastra, E.N. Dekleva, T. Saunders, C.P. Becerra, I.W. Tattersall, C.B. Westphalen, J. Kitajewski, M.G. FernandezBarrena, M.E. Fernandez-Zapico, C. Iacobuzio-Donahue, K.P. Olive, Stanger, stromal elements act to restrain, rather than support, pancreatic ductal adenocarcinoma. Cancer Cell 25, 735-747 (2014)

10. K. Eichelbaum, J. Krijgsveld (eds.), Exocytosis and Endocytosis. Methods in Molecular Biology (Humana Press, New York, 2014), pp. 101-114

11. N.S. Merle, S.E. Church, V. Fremeaux-Bacchi, L.T. Roumenina, Complement system part I - Molecular mechanisms of activation and regulation. Front. Immunol. (2015). https://doi.org/10.3389/ fimmu.2015.00262

12. G. Hajishengallis, E.S. Reis, D.C. Mastellos, D. Ricklin, J.D. Lambris, Novel mechanisms and functions of complement. Nat. Immunol. 18, 1288-1298 (2017)

13. V. Afshar-Kharghan, The role of the complement system in cancer. J. Clin. Invest. 127, 780-789 (2017)

14. M. Reichert, S. Takano, J. von Burstin, S.-B. Kim, J.-S. Lee, K. Ihida-Stansbury, C. Hahn, S. Heeg, G. Schneider, A.D. Rhim, B.Z. Stanger, A.K. Rustgi, The Prrx1 homeodomain transcription factor plays a central role in pancreatic regeneration and carcinogenesis. Genes Dev. 27, 288-300 (2013)

15. S.R. Hingorani, L. Wang, A.S. Multani, C. Combs, T.B. Deramaudt, R.H. Hruban, A.K. Rustgi, S. Chang, D.A. Tuveson, Trp53R172H and KrasG12D cooperate to promote chromosomal instability and widely metastatic pancreatic ductal adenocarcinoma in mice. Cancer Cell 7, 469-483 (2005)

16. Y. Kawashima, M. Satoh, T. Saito, T. Matsui, F. Nomura, H. Matsumoto, Y. Kodera, Cyclic sample pooling using twodimensional liquid chromatography system enhances coverage in shotgun proteomics. Biomed. Chromatogr. 27, 691-704 (2013)

17. J. Rappsilber, M. Mann, Y. Ishihama, Protocol for micro-purification, enrichment, pre-fractionation and storage of peptides for proteomics using StageTips. Nat. Protoc. 2, 1896-1906 (2007)

18. P.J. Roberts, C.J. Der, Targeting the Raf-MEK-ERK mitogenactivated protein kinase cascade for the treatment of cancer. Oncogene 14, 3291-3310 (2007)

19. Q. Yu, Y. Geng, P. Sicinski, Specific protection against breast cancers by cyclin D1 ablation. Nature 411, 1017-1021 (2001)

20. I. Peran, S. Madhavan, S.W. Byers, M.D. McCoy, Curation of the pancreatic ductal adenocarcinoma subset of the cancer genome atlas is essential for accurate conclusions about survival-related molecular mechanisms. Clin Cancer Res. 24, 3813-3819 (2018)
21. Á Nagy, A. Lánczky, O. Menyhárt, B. Győrffy, Validation of miRNA prognostic power in hepatocellular carcinoma using expression data of independent datasets. Sci. Rep. (2018). https:// doi.org/10.1038/s41598-018-27521-y

22. Y. Kiniwa, Y. Miyahara, H.Y. Wang, W. Peng, G. Peng, T.M. Wheeler, T.C. Thompson, L.J. Old, R.-F. Wang, CD8 + Foxp3 + regulatory $\mathrm{T}$ cells mediate immunosuppression in prostate cancer. Clin. Cancer Res. 13, 6947-6958 (2007)

23. S. Zhang, M. Wu, F. Wang, Immune regulation by $\mathrm{CD} 8^{+}$Treg cells: novel possibilities for anticancer immunotherapy. Cell. Mol. Immunol. 15, 805-807 (2018)

24. D. Ricklin, G. Hajishengallis, K. Yang, J.D. Lambris, Complement: a key system for immune surveillance and homeostasis. Nat. Immunol. 11, 785-797 (2010)

25. C. Kemper, J. Köhl, Back to the future-non-canonical functions of complement. Semin. Immunol. 37, 1-3 (2018)

26. E.S. Reis, D.C. Mastellos, D. Ricklin, A. Mantovani, J.D. Lambris, Complement in cancer: untangling an intricate relationship. Nat. Rev. Immunol. 18, 5-18 (2018)

27. M.G. Peters, J.L. Ambrus, A.S. Fauci, E.J. Brown, The Bb fragment of complement factor-B acts as a B-cell growth-factor. J. Exp. Med. 168, 1225-1235 (1988)

28. S. Makawita, C. Smith, I. Batruch, Y. Zheng, F. Rückert, R. Grützmann, C. Pilarsky, S. Gallinger, E.P. Diamandis, Integrated proteomic profiling of cell line conditioned media and pancreatic juice for the identification of pancreatic cancer biomarkers. Mol. Cell Proteomics (2011). https://doi.org/10.1074/mcp.M111. 008599

29. M.S. Cho, H.G. Vasquez, R. Rupaimoole, S. Pradeep, S. Wu, B. Zand, H.-D. Han, C. Rodriguez-Aguayo, J. Bottsford-Miller, J. Huang, T. Miyake, H.-J. Choi, H.J. Dalton, C. Ivan, K. Baggerly, G. Lopez-Berestein, A.K. Sood, V. Afshar-Kharghan, Autocrine effects of tumor-derived complement. Cell Rep. 6, 1085-1095 (2014)

30. P. Riihilä, L. Nissinen, M. Farshchian, M. Kallajoki, A. Kivisaari, S. Meri, R. Grénman, S. Peltonen, J. Peltonen, T. Pihlajaniemi, R. Heljasvaara, V.-M. Kähäri, Complement component C3 and complement factor B promote growth of cutaneous squamous cell carcinoma. Am. J. Pathol. 187, 1186-1197 (2017)

31. S. Goel, M.J. DeCristo, S.S. McAllister, J.J. Zhao, CDK4/6 inhibition in cancer: beyond cell cycle arrest. Trends Cell Biol. 28, 911925 (2018)

32. J.A. Ewald, J.A. Desotelle, G. Wilding, D.F. Jarrard, Therapyinduced senescence in cancer. J. Natl. Cancer Inst. 102, 15361546 (2010)

33. M. Milanovic, D.N.Y. Fan, D. Belenki, J.H.M. Däbritz, Z. Zhao, Y. Yu, J.R. Dörr, L. Dimitrova, D. Lenze, I.A. Monteiro Barbosa, M.A. Mendoza-Parra, T. Kanashova, M. Metzner, K. Pardon, M. Reimann, A. Trumpp, B. Dörken, J. Zuber, H. Gronemeyer, M. Hummel, G. Dittmar, S. Lee, C.A. Schmitt, Senescenceassociated reprogramming promotes cancer stemness. Nature $\mathbf{5 5 3}$, 96-100 (2018)

34. E. Karamitopoulou, Tumour microenvironment of pancreatic cancer: immune landscape is dictated by molecular and histopathological features. Br. J. Cancer. 121, 5-14 (2019)

35. Y. Wang, S.-N. Sun, Q. Liu, Y.-Y. Yu, J. Guo, K. Wang, B.-C. Xing, Q.-F. Zheng, M.J. Campa, E.F. Patz, S.-Y. Li, Y.-W. He, Autocrine complement inhibits IL10-dependent T-cell-mediated antitumor immunity to promote tumor progression. Cancer Discov. 6, 1022-1035 (2016)

36. J. Gadwa, T.E. Bickett, L.B. Darragh, M.W. Knitz, S. Bhatia, M. Piper, B. Van Court, S. Bhuvane, D. Nguyen, V. Nangia, E.K. Kleczko, R.A. Nemenoff, S.D. Karam, Complement C3a and C5a 
receptor blockade modulates regulatory $\mathrm{T}$ cell conversion in head and neck cancer. J. Immunother. Cancer (2021). https://doi.org/10. 1136/jitc-2021-002585

37. J. Fernandez-Retana, H. Zamudio-Meza, M. Rodriguez-Morales, A. Pedroza-Torres, D. Isla-Ortiz, L. Herrera, N. Jacobo-Herrera, O. Peralta-Zaragoza, C. López-Camarillo, F. Morales-Gonzalez, D. Cantu, C. de Leon, Pérez-Plasencia, Gene signature based on degradome-related genes can predict distal metastasis in cervical cancer patients. Tumor. Biol. (2017). https://doi.org/10.1177/ 1010428317711895

38. M.J. Lee, K. Na, S.-K. Jeong, J.-S. Lim, S.A. Kim, M.-J. Lee, S.Y. Song, H. Kim, W.S. Hancock, Y.-K. Paik, Identification of human complement factor B as a novel biomarker candidate for pancreatic ductal adenocarcinoma. J. Proteome Res. 13, 4878-4888 (2014)

39. S.H. Kim, M.J. Lee, H.K. Hwang, S.H. Lee, H. Kim, Y.-K. Paik, C.M. Kang, Prognostic potential of the preoperative plasma complement factor B in resected pancreatic cancer: A pilot study. Cancer Biomark. 24, 335-342 (2019)

Publisher's note Springer Nature remains neutral with regard to jurisdictional claims in published maps and institutional affiliations. 